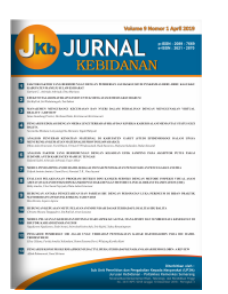

Volume 11 Nomor 1 (2021) 63-68

\author{
JURNAL KEBIDANAN \\ p-ISSN: 2089-7669 ; e-ISSN: 2621-2870 \\ http://dx.doi.org/10.31983/jkb.v11i1.6471
}

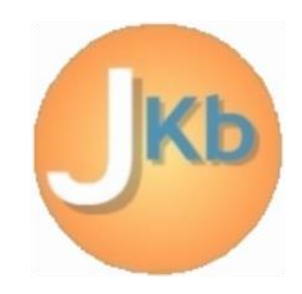

\title{
The Utilization of KIA Book in Padasuka Village in Sukarame Community Health Center
}

\author{
Fenty Agustini $^{1}$, Tupriliany Danefi ${ }^{2}$ \\ ${ }^{1,2}$ Department of Midwifery, Sekolah Tinggi Ilmu Kesehatan (STIKes) Respati \\ Jalan Raya Singaparna KM. 11 Cikunir Tasikmalaya, Indonesia \\ Corresponding author: Fenty Agustini \\ Email: fentyagustini86@gmail.com
}

Received: September 15, 2020 ; Revised: October 7th, 2020; Accepted: October $26^{\text {th }}, 2020$

\begin{abstract}
In 2018, there were 4 cases of maternal death and 6 cases of infant mortality in the Sukarame Puskesmas working area. An indirect cause of maternal death was being late in knowing the danger signs of pregnancy. There was an effort to anticipate this, the use of the KIA book. Currently, the distribution of KIA book in Indonesia had reached 94\%. However, although the 2016 national health survey data showed as many as $81.5 \%$ of pregnant women already had KIA book, only $60.5 \%$ of them could show the book and only $18 \%$ of the KIA book were completely filled. The purpose of this study was to describe the use of the MCH booklet by mothers of children under five. The research method in this research was descriptive method to describe the use of the KIA book in Padasuka Village. The results showed that most of the perceptions of the KIA book were in the positive category, namely $92.31 \%$, bringing the KIA book to health facilities in the carrying category was $61.54 \%$, carrying the KIA book to the posyandu $100 \%$, keeping the KIA book in the maintained category of $62,82 \%$, asked if there was something unclear from the KIA book for the question category of $73.08 \%$, knowledge of the good category was $33.33 \%$. The conclusion of this study was most mothers had used the KIA book including positive perceptions of the KIA book, brought the KIA book to the posyandu and brought the KIA book to other health services, the condition of the KIA book was maintained, mostly pregnant women asked health workers, but $66.67 \%$ of mothers had not read the KIA book, which was in the poor category.
\end{abstract}

Keyword: utilization; KIA book; mothers of toddlers

\section{Pendahuluan}

Angka Kematian Ibu (AKI) dan Angka Kematian Bayi (AKB) di Indonesia masih tinggi bila dibandingkan dengan Negara Asia lainnya. Menurut SDKI AKI di Indonesia adalah 359/100.000 kelahiran hidup. Sedangkan jumlah AKB di Indonesia menurut SDKI 2012 sebesar 32/1.000 kelahiran hidup[1].

Target AKI Indonesia sesuai SDGs (Sustainable Development Goals) 2030 adalah mengurangi AKI hingga di bawah 70 per 100.000 kelahiran hidup, menurunkan Angka Kematian
Neonatal hingga 12 per $1000 \mathrm{KH}$ dan Angka Kematian Balita 25 per $1000 \mathrm{KH}$. Untuk mencapai target tersebut perlu upaya percepatan yang lebih besar dan kerjasama antara tenaga kesehatan[2].

Kebijakan dan berbagai upaya pemerintah untuk menurunkan angka kematian ibu dan bayi, antara lain dengan Gerakan Sayang Ibu (GSI), Strategi Making Pregnancy Safer dan pengadaan buku Kesehatan Ibu dan Anak. Buku KIA adalah alat untuk mendeteksi secara dini adanya gangguan atau masalah kesehatan ibu dan anak, alat komunikasi dan penyuluhan dengan 
informasi yang penting bagi ibu, keluarga dan masyarakat mengenai pelayanan, kesehatan ibu dan anak termasuk rujukannya dan pekat (standar) pelayanan KIA, gizi, imunisasi, dan tumbuh kembang balita [3-4].

Setiap jam di Indonesia dilaporkan $2 \mathrm{ibu}$ meninggal saat hamil atau bersalin. Memang secara klinis penyebab utama kematian pada ibu hamil adalah perdarahan. Adapun penyebab lain itu diantaranya karena tiga terlambat, yaitu yang pertama adalah terlambat mengetahui tanda bahaya kehamilan sehingga terlambat pula dalam mengambil keputusan untuk mencari pertolongan. Akibatnya perdarahan yang sebenarnya bisa ditangani oleh petugas kesehatan berakhir fatal karena pasien telambat ditolong. Yang kedua adalah terlambat menyediakan transportasi pada saat akan melahirkan. Sedangkan yang ketiga adalah terlambat memperoleh pertolongan segera saat tiba di fasilitas kesehatan [5].

Salah satu faktor penyebab tidak langsung dari kematian ibu yaitu terlambat mengetahui tanda bahaya kehamilan. Untuk dapat mengantisipasi hal tersebut maka diperlukan suatu upaya untuk dapat mengenali komplikasi kehamilan atau tanda bahaya kehamilan. Salah satunya adalah dengan pemanfaatan buku KIA yang didalamnya berisi informasi tentang tanda bahaya kehamilan. Untuk dapat mengenali tanda bahaya kehamilan maka ibu hamil perlu diberikan pengetahuan agar dapat bersikap positif dan agar dapat melakukan tindakan yang tepat saat menemui tanda tanda bahaya kehamilan [6].

Buku KIA merupakan sebuah buku program secara nasional yang berisi informasi dan materi penyuluhan tentang gizi, kesehatan ibu dan anak, kartu ibu hamil, KMS Balita dan catatan pelayanan kesehatan ibu dan anak. Buku KIA disimpan di rumah dan dibawa setiap kali ibu dan anak datang ke Posyandu. Setiap ibu hamil mendapatkan satu buku KIA dan digunakan sampai anak berusia lima tahun. Dengan buku KIA kondisi kesehatan ibu dan anak dapat dicatat serta berisi informasi tentang kesehatan, sehingga perkembangan balita dapat terpantau berdasarkan catatan yang ada dalam buku KIA.

Saat ini persebaran buku KIA di Indonesia sudah mencapai $94 \%$. Akan tetapi meskipun data survei kesehatan nasional menunjukkan sebanyak $81,5 \%$ ibu hamil telah memiliki buku KIA, hanya $60,5 \%$ di antaranya yang bisa menunjukkan dan hanya sebanyak $18 \%$ buku KIA yang terisi lengkap[7]. Kabupaten
Tasikmalaya merupakan daerah dengan angka kematian ibu tertinggi ke-3 di Jawa Barat, pada tahun 2016 Angka Kematian Ibu di Kabupaten Tasikmalaya adalah 145,23/100.000 KH dan angka kematian bayi tertinggi ke-4 yaitu pada tahun 2016 sebesar 8,23/1000 KH. Pada tahun 2018 di Wilayah Kerja Puskesmas Sukarame terdapat 4 kasus kematian ibu dan 6 kasus kematian bayi. Pada tahun 2017 kejadian stunting di Desa Padasuka dengan kategori pendek sebanyak 91 dari 389 balita $(23,4 \%)$ dan pada tahun 2018 mengalami kenaikan sebesar 9,2\% dengan kategori sangat pendek sebanyak 32 dari 368 balita $(8,7 \%)$ dan kategori pendek sebanyak 88 dari 368 balita $(23,9 \%)$ [8].

Pemanfaatan buku KIA menjadi salah satu faktor penting dalam pencegahan masalah diatas, berdasarkan informasi yang diperoleh sebagian besar Ibu tidak membaca isi Buku KIA padahal buku KIA memuat informasi yang sangat penting. Berdasarkan latar belakang tersebut peneliti tertarik untuk meneliti gambaran pemanfaatan buku KIA oleh Ibu Balita di Desa Padasuka Wilayah Kerja Puskesmas Sukarame Kabupaten Tasikmalaya Tahun 2019.

\section{Metode Penelitian}

Jenis penelitian ini termasuk kuantitatif dengan menggunakan metode deskriptif. Populasi dalam penelitian ini adalah seluruh ibu balita di Desa Padasuka Wilayah Kerja Puskesmas Sukarame Kabupaten Tasikmalaya berjumlah 357 orang. Pengambilan sampel ditentukan berdasarkan perhitungan yaitu sebesar 78 orang. Sebelum dilakukan penelitian dilaksanakan etical clearence dengan Nomor : 201/kepk-bth/12/2019. Penelitian dilaksanakan pada Bulan NovemberDesember 2019 bertempat di Desa Padasuka Wilayah Kerja Puskesmas Sukarame Kabupaten Tasikmalaya. Peneliti menggunakan skala likert untuk mengetahui variabel persepsi sebanyak 10 pernyataan, variabel baca buku KIA dengan dengan bentuk multiple choice sebanyak 20 soal, bawa buku KIA sebanyak 2 pertanyaan, tanya buku KIA sebanyak 1 pertanyaan dan lembar observasi untuk jaga buku KIA sebanyak 1 pertanyaan. Serta untuk jaga buku KIA sebanyak 1 pertanyaan. Pengambilan data ini menggunakan data primer sehingga peneliti langsung mengukur variabel yang diteliti. Kemudian peneliti memberikan pertanyaan dengan mendatangi posyandu untuk memperoleh data tentang pemanfaatan buku KIA. 


\section{Hasil dan Pembahasan}

Tabel 1

Karakteristik Responden

\begin{tabular}{clccc}
\hline No & & Variabel & Frekuensi & Persentase \\
\hline 1 & Paritas Ideal & 41 & 82 \\
& Tidak ideal & 9 & 18 \\
2 & Umur & Min : 17 & Max : 45 \\
3 & Pendidikan & 42 & 53,85 \\
& Rendah & 32 & 41,02 \\
& Menengah & 4 & 5,13 \\
& Tinggi & & \\
\hline
\end{tabular}

Tabel 2

Pemanfaatan Buku KIA

\begin{tabular}{clcc}
\hline No & \multicolumn{1}{c}{ Variabel } & Frekuensi & Persentase \\
\hline 1 & Persepsi & 72 & \\
& Postif & 6 & 92,31 \\
& Negatif & & 7,69 \\
2 & Bawa Buku KIA ke Fasilitas Kesehatan & 48 & 61,54 \\
& Bawa & 30 & 38,46 \\
& Tidak Bawa & & \\
& Bawa Buku KIA ke Posyandu & 78 & 100 \\
& Bawa & 0 & 0 \\
& Tidak Bawa & & 62,82 \\
3 & Jaga Buku KIA & 49 & 37,18 \\
& Terawat & 29 & 73,08 \\
4 & Tidak Terawat & & 26,92 \\
& Tanya Buku KIA & 57 & 33,33 \\
& Bertanya & 21 & 66,67 \\
\hline
\end{tabular}

Tabel 1 menunjukkan karakteristik responden bahwa sebagian besar responden memiliki paritas ideal (paritas tidak lebih dari 2) yaitu sebanyak 41 responden atau sebesar $82 \%$ dengan umur minimal 17 tahun dan maksimal 45 tahun dan rata-rata umur yaitu 30-31 tahun. Sebagian besar pendidikan responden termasuk kategori rendah yaitu sebanyak 42 responden atau sebesar $53,85 \%$.

Tabel 2 menunjukkan pemanfaatan buku KIA meliputi persepsi buku KIA pada ketegori positif sebesar 92,31\% dan negative sebesar 7,69 $\%$. responden yang membawa buku KIA ke fasilitas kesehatan pada kategori bawa sebesar 61,54\% dan tidak bawa sebesar 38,46 \% dan sebanyak $100 \%$ membawa buku KIA ke posyandu. Menjaga Buku KIA pada kategori terawat sebesar $62,82 \%$ dan tidak terawat sebesar $37,18 \%$. Kategori bertanya apabila ada yang kurang difahami dalam buku KIA sebesar 73,08 $\%$ dan tidak bertanya sebesar $26,92 \%$. Responden yang memiliki pengetahuan kategori baik sebesar $33,33 \%$ dan kurang sebesar $66,67 \%$ yang mengindikasikan bahwa sebagian besar responden tidak membaca buku KIA sehingga pengetahuan ibu tentang isi buku KIA kurang.

Pengertian Buku KIA adalah alat yang sederhana sebagai alat informasi, Edukasi dan Komunikasi dalam menyebarkan informasi penting mengenai Kesehatan Ibu dan Anak (KIA) kepada keluarga. Buku KIA merupakan alat untuk mendeteksi secara dini adanya gangguan atau masalah pada ibu dan anak, alat komunikasi dan penyuluhan dengan informasi yang penting bagi 
ibu, keluarga, dan masyarakat mengenai pelayanan kesehatan ibu dan anak termasuk rujukannya dan paket (standar) pelayanan KIA, gizi, imunisasi, dan tumbuh kembang balita. Buku KIA merupakan buku wajib untuk dibaca oleh ibu hamil, suami dan anggota keluarga karena berisikan informasi penting dan berguna bagi kesehatan ibu dan anak. Buku kesehatan selain sebagai catatan kesehatan ibu dan anak, juga dimaksudkan sebagai alat monitor kesehatan dan alat komunikasi antara tenaga kesehatan dengan pasien, sehingga dapat diharapkan partisipasi masyarakat dalam mengontrol kesehatan ibu dan anak. Kewajiban ibu hamil dalam pemanfaatkan buku KIA terdiri dari baca buku KIA, bawa buku KIA, jaga buku KIA dan tanya ke petugas kesehatan [9]. Pemanfaatan buku KIA bisa meningkatkan pengetahuan dan diaplikasikan dalam menjaga kesehatan ibu hamil sehingga meningkatkan derajat kesehatan ibu hamil dan janinnya. Pemanfaatan ini dilakukan oleh petugas kesehatan dan ibu hamil serta keluarganya dengan cara membaca informasi kesehatan di dalam buku KIA[10].

Persepsi buku KIA pada ketegori positif sebesar 92,31\% dan negative sebesar 7,69\%. ibu yang memiliki persepsi negatif sebagian besar memiliki persepsi bahwa buku KIA tidak ada pengaruh bagi kesehatan ibu dan hanya boleh dibaca oleh ibu saja. Persepsi merupakan suatu proses yang didahului oleh penginderaan, yaitu suatu stimulus yang diterima oleh individu melalui alat reseptor yaitu indera. Alat indera merupakan penghubung antara individu dengan dunia luarnya. Persepsi merupakan stimulus yang diindera oleh individu, diorganisasikan kemudian diinterpretasikan sehingga individu menyadari dan mengerti tentang apa yang diindera. Dengan kata lain persepsi adalah proses yang menyangkut masuknya pesan atau informasi ke dalam otak manusia[11]. Penelitian oleh Musdalina menunjukkan hasil bahwa sebagian besar responden mempunyai persepsi kurang baik tentang keberadaan buku KIA (61,3\%). Dikarekan buku KIA tidak ada pengaruh bagi kesehatan ibu, buku KIA tidak boleh dibaca oleh suami dan anggota keluarga lain karena berisi informasi untuk kesehatan ibu dan anak saja dan gambar yang ada di dalam buku KIA sangat tidak menarik dan tidak mudah dimengerti oleh ibu dan keluarga [12]. Menurut Azwar Sikap adalah keteraturan tertentu dalam hal perasaan (afeksi), pemikiran (kognitif), dan predisposisi tindakan (konasi) seseorang terhadap suatu aspek di lingkungan sekitarnya[13].
Berdasarkan pembahasan tersebut dapat disimpulkan bahwa, Semakin baik persepsi ibu tentang manfaat buku KIA maka semakin tinggi pula pemanfaatan buku KIA. Ibu dengan persepsi baik tentang buku KIA akan memanfaatkan buku KIA lebih baik dibandingkan ibu dengan persepsi yang kurang baik. Responden yang membawa buku KIA ke fasilitas kesehatan pada kategori bawa sebesar $61,54 \%$ dan tidak bawa sebesar $38,46 \%$. Sedangkan sebanyak $100 \%$ responden membawa buku KIA ke posyandu. Menurut K.K.RI dalam "Petunjuk Teknis Penggunaan Buku Kesehatan Ibu Dan Anak buku KIA ini dibawa oleh ibu hamil dan diberikan kepada petugas kesehatan setiap kali ke Posyandu, Polindes, Puskesmas, bidan/dokter praktik swasta dan rumah sakit, karena salah satu manfaat dari buku KIA untuk mencatat dan alat memantau serta memonitoring kesehatan ibu dan anak. Berdasarkan hal tersebut penulis berasumsi bahwa masih terdapat ibu yang kurang memahami bahwa Buku KIA tidak hanya dibawa ke Posyandu saja akan tetapi harus dibawa ke semua pelayanan kesehatan agar kesehatan ibu dan anak selalu terpantau[9].

Responden yang menjaga Buku KIA pada kategori terawat sebesar $62,82 \%$ dan tidak terawat sebesar $37,18 \%$. Menurut K.K.RI dalam "Petunjuk Teknis Penggunaan Buku Kesehatan Ibu Dan Anak buku KIA ini harus disimpan, jangan sampai hilang karena berisi catatan kesehatan ibu dan anak. Catatan yang ada di dalam buku ini akan sangat bermanfaat bagi ibu, anak dan petugas kesehatan. Peneliti berasumsi bahwa masih terdapat ibu yang belum memahami tentang kewajiban ibu terhadap buku KIA. Sebagian tidak terlalu menganggap penting tentang informasi yang terdapat dalam buku KIA[9].

Responden yang bertanya apabila ada yang kurang jelas dari buku KIA untuk kategori bertanya sebesar $73,08 \%$ dan tidak bertanya sebesar $26,92 \%$. Tanya ke bidan, dokter, atau petugas kesehatan lainnya jika ada hal-hal yang ingin diketahui ada masalah kesehatan ibu dan anak. Jangan malu dan jangan ragu untuk bertanya[9].

Responden yang memiliki pengetahuan kategori baik sebesar 33,33\% dan kurang sebesar 66,67 \%. Menurut K.K.RI dalam "Petunjuk Teknis Penggunaan Buku Kesehatan Ibu dan Anak Buku KIA ini merupakan buku pintar untuk ibu hamil, maka kewajiban bagi ibu hamil untuk membaca secara keseluruhan Buku KIA ini karena berisi informasi yang sangat berguna untuk 
kesehatan ibu dan anak. Buku KIA mencakup informasi mengenai ibu hamil, ibu bersalin, ibu nifas, keluarga berencana $(\mathrm{KB})$, catatan pelayanan kesehatan ibu dan kesehatan anak. Hasil penelitian [9][14], memanfaatkan buku KIA dengan membaca informasi di dalamya membuat ibu hamil mengerti perilaku kesehatan ibu hamil yang harus dilakukan, melakukan intervensi yang terdapat di dalam buku KIA, melakukan pemeriksaan apa saja yang harus dilakukan dan bisa dibawa saat melakukan pemeriksaan di berbagai fasilitas kesehatan, kapan saja dan dimana saja sehingga terwujud pemantauan kesehatan ibu dan janin secara berkala sebagai awal terlaksananya Continuity of Care. Berdasarkan hasil penelitian didapatkan bahwa rata rata umur adalah 30,7 tahun, umur minimal 17 tahun dan umur maksimal 45 tahun. Menurut Notoatmodjo usia sangat erat hubungannya dengan pengetahuan seseorang, karena semakin bertambah usia maka semakin banyak pula pengetahuannya. Sebagian besar responden yaitu sebesar 53,85\% dan termasuk kategori menengah sebesar $41,02 \%$. Semakin cukup umur, tingkat kemantangan dan kekuatan seseorang akan lebih matang dalam berpikir dan bekerja jadi semakin matangnya umur seorang remaja semakin matang pula pemikirannya soal kesehatan [15] [16].

Pendidikan secara umum adalah segala upaya yang direncanakan untuk mempengaruhi orang lain baik individu, kelompok masyarakat sehingga mereka memperoleh tujuan yang diharapkan Sehingga mampu untuk meningkatkan kesehatan. Salah satu faktor yang mempengaruhi pengatahuan adalah pendidikan [17].

Semakin tinggi pendidikan seseorang makin mudah. Pendidikan dapat mempengaruhi seseorang termasuk pola hidup terutama dalam memotivasi untuk siap berperan serta dalam pembangunan kesehatan. Latar belakang pendidikan ibu yang rendah akan menyulitkan berlangsungnya penyampaian informasi kesehatan terhadap ibu karena mereka kurang menyadari pentingnya informasi-informasi tentang kesehatan. Tingkat pendidikan seseorang berpengaruh dalam memberikan respon terhadap sesuatu yang datang dari luar. Seseorang yang mempunyai tingkat pendidikan tinggi akan memberikan respon yang lebih rasional dan juga dalam motivasi kerjanya akan berpotensi dari pada mereka yang berpendidikan lebih rendah atau sedang. Maka visi pendidikan adalah mencerdaskan manusia. Tingkat pendidikan turut menentukan mudah tidaknya seseorang memahami tentang tanda-tanda bahaya kehamilan. Hasil penelitian menunjukkan bahwa paritas pada ketegori ideal sebesar $82 \%$ dan tidak ideal sebesar $18 \%$. Berdasarkan hasil penelitian C. E. A. Sistiarani menyebutkan bahwa pengetahuan yang baik mengenai Buku KIA akan dapat meningkatkan kepatuhan ibu dalam pemanfaatan Buku KIA, sehingga kualitas pemanfaatan Buku KIA akan meningkat. Ibu yang membaca dan memahami informasi/ pesan dalam Buku KIA merupakan determinan penting pengetahuan ibu dalam KIA[18].

Menurut Notoatmodjo pengetahuan sangat erat hubungannya dengan paritas karena semakin sering seseorang wanita melahirkan semakin banyak pengalaman pribadi yang diperoleh dan dapat menuntun seseorang dalam menarik kesimpulan. Dalam penelitian ini pengetahuan ibu berbanding terbalik dengan paritas ibu, hal ini dimungkinkan bahwa paritas bukan merupakan satu-satunya faktor yang mempengaruhi pengetahuan seseorang, terdapat faktor lain diantaranya umur dan tingkat pendidikan ibu[15].

\section{Simpulan}

Kesimpulan dari penelitian ini adalah sebagin besar ibu sudah memanfaatkan buku KIA meliputi persepsi buku KIA sebagian besar positif yaitu $93,31 \%$, sebanyak $100 \%$ membawa buku KIA ke posyandu dan sebanyak $61,54 \%$ membawa buku KIA ke pelayanan kesehatan lain, sebanyak $62,82 \%$ kondisi buku KIA terawat, sebanyak $73,08 \%$ bertanya kepada petugas kesehatan, akan tetapi sebanyak 66,67\% tidak membaca buku KIA terbukti dari pengetahuan ibu sebanyak $66,67 \%$ termasuk kategori kurang. Saran bagi tenaga kesehatan maupun kader agar lebih meningkatkan pemahaman bagi ibu terkait dengan pemanfaatan buku KIA dengan melaksanakan penyuluhan maupun sosialisasi kepada ibu terkait dengan pemanfaatan buku KIA terutama memberikan pemahaman tentang pentingnya membaca buku KIA.

\section{Ucapan Terimakasih}

Dengan memanjatkan puji dan syukur kehadirat Alloh SWT atas segala nikmat dan karuanianya sehingga peneliti dapat menyelesaikan penelitian ini. Terselesaikannya penelitian tidak terlepas dari bantuan berbagai pihak. Untuk itu peneliti mengucapkan terimakasih kepada STIKes Respati atas segala 
dukungannya baik moril maupun materil berupa pendanaan penelitian, serta seluruh pihak yang telah membantu terselenggaranya kegiatan penelitian ini dengan baik

\section{Daftar Pustaka}

[1] Survey Demografi Kesehatan Indonesia, "Survey Demografi Kesehatan Indonesia," Jakarta, 2012.

[2] K. RI, "Kesehatan Dalam Kerangka Sustainable Development Goals (SDGs)," Jakarta, 2015.

[3] A. Wiratih, "Tingkat Pengetahuan Ibu Hamil Tentang Buku Kesehtan Ibu Dan Anak (KIA) di BPS Titik Desa Padas Kecamatan Tanon Kabupaten Sragen Tahun 2013.," J. Keperawatan., vol. 1, no. 2, 2013.

[4] M. D. dr. D. O. Moegni, Prof. dr. Endy, Buku Saku Pelayanan Kesehatan Ibu Di Fasilitas Kesehatan Dasar Dan Rujukan. Jakarta: UNFPA, Unicef, USAID, 2013.

[5] Badan Penelitian dan Pengembangan Kesehatan Kementrian Kesehatan Republik Indonesia, "Riset Kesehatan Dasar," Jakarta, 2010.

[6] Suryani, "Hubungan pengetahuan dan status ekonomi dengan status gizi ibu hamil di Puskesmas Putri Ayu Kota Jambi," 2009.

[7] B. P. P. K. K. K. R. SIRKESNAS, "Survei Indikator Kesehatan Nasional," Jakarta, 2016.

[8] D. K. KabupatenTasikmalaya, "Profil Dinas Kesehatan Tasikmalaya," 2016.

[9] K. K. RI, "Petunjuk Teknis Penggunaan Buku Kesehatan Ibu Dan Anak," Jakarta,
2015.

[10] S. Isaranurug, "Maternal and Child Health $(\mathrm{MCH})$ Handbook in The Word Maternal and Child Health Handbook in Thiland," J. Int. Heal. ASEAN Inst. Heal. Dev. Mahidol Univrsity, Thail., vol. 24, no. 2, 2009.

[11] B. Walgito, Pengantar Psikologi Umum. Yogyakarta, 2010.

[12] Musdalina, "Hubungan Karakteristik Dan Persepsi Ibu Tentang Buku Kesehatan Ibu Dan Anak (KIA) Dengan Pemanfaatan Buku KIA Pada Pelayanan Antenatal Care (ANC) Di Puskesmas Stabat Kecamatan Stabat Kabupaten Langkat," 2015.

[13] Azwar, Sikap Manusia, Teori dan Pengukurannya. Yogyakarta: Pustaka Belajar, 2014.

[14] Y. Baiquni, Nakamura, "Is Maternal and Child Helath Handbook Effective? MetaAnalysis of The Effects of MCH Handbook," J. Int. Heal., vol. 27, no. 2, 2012.

[15] S. Notoatmodjo, Pendidikan dan Perilaku Kesehatan. Jakarta, 2007.

[16] Nursalam, Pendekatan Praktis Metode Riset Keperawatan. Jakarta: Perpustakaan Nasional RI, 2013.

[17] A. D. Wawan, Teori dan Pengukuran Pengetahuan, Sikap dan Perilaku Manusia. Yogyakarta: Nuha Medika, 2010.

[18] C. E. A. Sistiarani, "Fungsi Pemanfaatan Buku KIA Terhadap Pengetahuan Kesehatan Ibu Dan Anak Pada Ibu Function Of Utilization Maternal Child Health Book To Maternal Knowledge,," J. Kesehat. Masy. Nas., vol. 8, no. 8, pp. 353-358, 2014. 